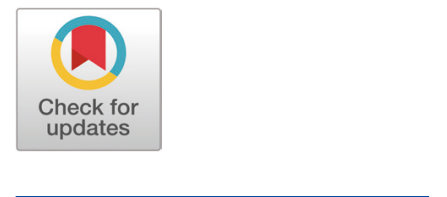

Received: Mar 4, 2020

Accepted: Mar 19, 2020

*Corresponding author Geun-Bae Kim

Department of Animal Science and Technology, Chung-Ang University, Anseong 17546, Korea.

Tel: +82-31-670-3027

E-mail: kimgeun@cau.ac.kr

Copyright $@ 2020$ Korean Society of Animal Sciences and Technology. This is an Open Access article distributed under the terms of the Creative Commons Attribution Non-Commercial License (http:// creativecommons.org/licenses/by$\mathrm{nc} / 4.0 /$ ) which permits unrestricted non-commercial use, distribution, and reproduction in any medium, provided the original work is properly cited.

ORCID

Ju-Eun Lee

https://orcid.org/0000-0002-6467-1562

Sunhak Heo

https://orcid.org/0000-0002-2133-8540

Geun-Bae Kim

https://orcid.org/0000-0001-8531-1104

Competing interests

No potential conflict of interest relevant to this article was reported.

Funding sources

This manuscript has not received any funding.

Acknowledgements

Not applicable.

Availability of data and material Upon reasonable request, the datasets of this study can be available from the corresponding author.

\section{Complete genome sequence of Streptococcus hyointestinalis B19, a strain producing bacteriocin, iso- lated from chicken feces}

\author{
Ju-Eun Lee, Sunhak Heo and Geun-Bae Kim* \\ Department of Animal Science and Technology, Chung-Ang University, Anseong 17546, Korea
}

\begin{abstract}
Streptococcus hyointestinalis B19 was isolated from chicken feces collected from local farm in Anseong, Korea. S. hyointestinalis B19 was shown to produce bacteriocin-like compounds exhibiting inhibitory activities against several pathogens including strains of Clostridium perfringens and Listeria monocytogenes. The whole genome of S. hyointestinalis B19 strain was sequenced using PacBio RS II platform. The genome comprised four contigs with a size of $2,217,061 \mathrm{bp}$. The DNA G + C content was found to be $42.95 \mathrm{~mol} \%$. Annotation results revealed 2,266 coding sequences (CDSs), 18 rRNAs, and 61 tRNA genes. Based on genome analysis, we found that the strain B19 possessed various genes associated with bacteriocin synthesis, modification, and transport.
\end{abstract}

Keywords: Streptococcus hyointestinalis B19, Whole genome, Chicken feces, Bacteriocin

In recent years, there have been increasing studies to find alternatives to antibiotics, such as antibodies, probiotics, bacteriophages, and bacteriocins because of the increase in antibiotic resistance [1,2]. In our previous study, we reported that $S$. hyointestinalis B19 has potential to be used in similar applications [3]. S. hyointestinalis B19 strain was found to produce antimicrobial protein molecules, which possess characteristics similar to those of bacteriocin (heat stability). The selected strains of Clostridium perfringens and Listeria monocytogenes were strongly inhibited by the strain B19. To confirm whether the antimicrobial substance is bacteriocin and to better understand the characteristics of the molecule, we carried out whole genome sequencing of the strain B19.

S. hyointestinalis B19 was isolated from chicken fecal samples collected from local farm in Anseong, Korea. The genomic DNA was extracted from the strain B19 cultured to stationary phase in M17 medium supplemented with $0.5 \%$ (w/v) glucose using QIAamp PowerFecal DNA Kit (Qiagen) according to the manufacturer's instructions. The whole genome of strain B19 was sequenced using Pacific Biosciences (PacBio) RS II Single Molecule Real Time (SMRT) platform with a $20 \mathrm{~kb}$ SMRTbell $^{\mathrm{TM}}$ template library at ChunLab. The reads were assembled on PacBio SMAR Analysis 2.3.0. Genome analysis and annotation were performed by CLgenomics ${ }^{\mathrm{TM}}$ v. 1.55 software. Transfer RNAs (tRNAs) were identified using tRNAscan-SE v. 1.3.1. Ribosomal RNAs (rRNAs) and non-coding RNAs (ncRNAs) were identified using INFERNAL v. 1.0.2 with Rfam 12.0 database. For CRISPR, PilerCR v. 1.06 and CRT v. 1.2 were used. Protein-coding sequences (CDSs) were identified by using PRODIGAL v. 2.6.2 [4] and compared to protein databases (SwissProt, KEGG, SEED, EggNOG) using USEARCH v. 8.1 
Authors' contributions Conceptualization: Kim GB.

Data curation: Lee JE.

Formal analysis: Heo S.

Investigation: Lee JE, Heo S, Kim GB.

Writing - original draft: Lee JE.

Writing - review \& editing: Lee JE, Kim GB.

Ethics approval and consent to participate This manuscript does not require IRB/IACUC approval because there are no human and animal participants.
[5] for functional annotation. The draft genome of S. hyointestinalis B19 consisted of a 2,217,061 bp chromosome with a $\mathrm{G}+\mathrm{C}$ content of $42.95 \%$ (Table 1). The genome contained 2,266 coding sequences (CDSs), 18 rRNAs, and 61 tRNA genes (Fig. 1).

The mining of the bacteriocinogenic gene clusters was performed by using the BAGEL4 platform [6]. The genome possessed $t h m A$-, thmB-like genes, and bovicin 255-like genes. The former genes encode peptides ThmA and ThmB, respectively, that form Thermophilin 13, the bacteriocin

Table 1. Genome features of Streptococcus hyointestinalis B19

\begin{tabular}{lc}
\hline \multicolumn{1}{c}{ Property } & Value \\
\hline Genome assembly & \\
Assemble method & SMAR analysis version 2.3 .0 \\
Genome coverage & $438.91 x$ \\
Genome features & \\
Genome size (bp) & $2,217,061$ \\
No. of contigs & 4 \\
G + C content (\%) & 42.95 \\
Protein-coding genes (CDSs) & 2,266 \\
rRNA genes & 18 \\
tRNA genes & 61 \\
Plasmids & 0 \\
Genbank accession No. & JAAKGB000000000 \\
\hline
\end{tabular}

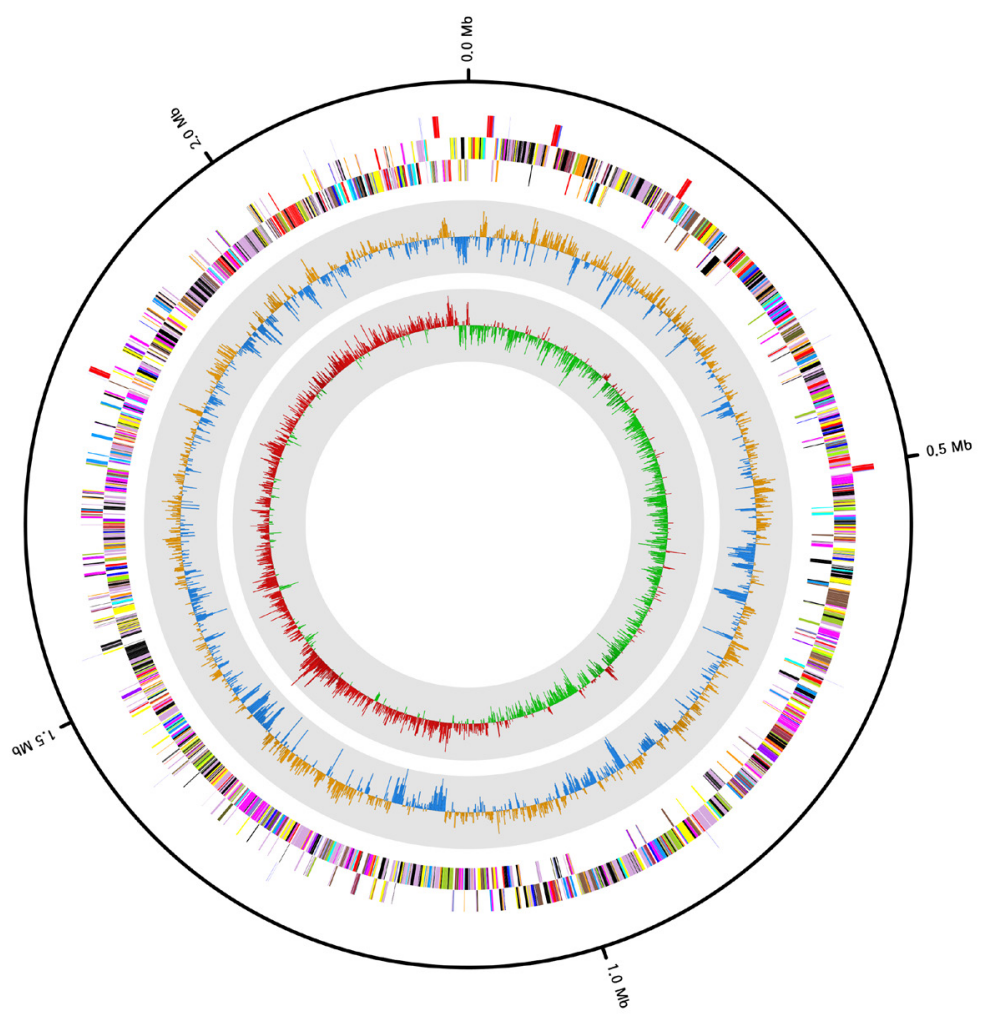

Fig. 1. Circular genome map of Streptococcus hyointestinalis B19. From the outermost circle to the center, each circle indicates information about tRNA/rRNA, forward and reverse coding sequences (CDSs), GC ratio, and GC skew. 
first isolated from S. thermophilus [7]. Strain 19 also contains the genes associated with ABC-transporter and bacteriocin immunity for bacteriocin export and self-immunity to bacteriocin, respectively. These two genes are common members of the lantibiotic gene clusters [8].

Nucleotide sequence accession number

The GenBank/EMBL/DDBJ accession number for the genome sequence of S. hyointestinalis B19 is JAAKGB000000000.

\section{REFERENCES}

1. Czaplewski L, Bax R, Clokie M, Dawson M, Fairhead H, Fischetti VA, et al. Alternatives to antibiotics-a pipeline portfolio review. Lancet Infect Dis. 2016;16:239-51.

2. Joerger RD. Alternatives to antibiotics: bacteriocins, antimicrobial peptides and bacteriophages. Poult Sci. 2003;82:640-7.

3. Heo S, Kim MG, Kwon M, Lee HS, Kim GB. Inhibition of Clostridium perfringens using bacteriophages and bacteriocin producing strains. Korean J Food Sci Anim Resour. 2018;38:8898.

4. Hyatt D, Chen GL, Locascio PF, Land ML, Larimer FW, Hauser LJ. Prodigal: prokaryotic gene recognition and translation initiation site identification. BMC Bioinformatics. 2010;11:119.

5. Edgar RC. Search and clustering orders of magnitude faster than BLAST. Bioinformatics. 2010;26:2460-1.

6. van Heel AJ, de Jong A, Song C, Viel JH, Kok J, Kuipers OP. BAGEL4: a user-friendly web server to thoroughly mine RiPPs and bacteriocins. Nucleic Acids Res. 2018;46:W278-81.

7. Marciset O, Jeronimus-Stratingh MC, Mollet B, Poolman B. Thermophilin 13, a nontypical antilisterial poration complex bacteriocin, that functions without a receptor. J Biol Chem. 1997;272:14277-84.

8. McAuliffe O, Ross RP, Hill C. Lactibiotics: structure, biosynthesis and mode of action. FEMS Microbiol Rev. 2001;25:285-308. 